\title{
Clinical assessment of oxygen conserving devices in chronic bronchitis and emphysema
}

\author{
GA GOULD, MD HAYHURST, W SCOTT, DC FLENLEY \\ From the Rayne Laboratory, Department of Respiratory Medicine, University of Edinburgh, City Hospital, \\ Edinburgh
}

ABSTRACT We have studied the efficacy of three devices designed to conserve oxygen delivered to patients with hypoxic chronic bronchitis and emphysema. Devices A and B are valve systems, which deliver oxygen only during inspiration. Device $C$ is a modified nasal prongs system incorporating a "moustache reservoir" (Oxymizer, Chad Therapeutics Inc, Woodland Hills, California), which is claimed to produce a higher arterial oxygen saturation $\left(\mathrm{SaO}_{2}\right)$ from a given flow of oxygen than does continuous delivery through nasal prongs. Devices $\mathrm{A}$ and $\mathrm{B}$ were found to give the same oxygen saturation as continuous flow oxygen, but only device $B$ reduced the flow of oxygen significantly $(\mathrm{p}<0.01)$. The flow characteristics of device $\mathrm{A}$ were likely to be the cause of this failure to conserve oxygen. Device $\mathrm{C}$ produced a higher mean rise in $\mathrm{SaO}_{2}$ than did standard nasal prongs at all oxygen flow rates, and was able to achieve the same rise in $\mathrm{SaO}_{2}$ as standard nasal prongs with a small (25-33\%) saving in oxygen delivery. There was, however, considerable variation between patients in the oxygen saving efficiency of device $\mathrm{C}$, with little or no oxygen saving in seven of the 12 patients studied.

Long term domiciliary oxygen treatment can prolong life in patients with hypoxic chronic bronchitis and emphysema, ${ }^{12}$ but it is expensive ${ }^{3}$ and the size of equipment restricts the patient's mobility. A device that conserves oxygen while maintaining adequate blood oxygenation could reduce the cost and might also allow reduction in the size of equipment, with a subsequent improvement in the patient's mobility. We have evaluated three such devices, which all aim to reduce the oxygen wasted during expiration, by assessing their clinical efficacy.

\section{Description of equipment}

Device $A$ is a regulating valve, which is connected between the oxygen supply and the nasal prongs that deliver the oxygen to the patient. It incorporates a microprocessor switch sensitive to pressure changes during the respiratory cycle, so that the valve allows oxygen flow only during inspiration. An additional feature is incorporated so that the valve opens

Address for reprint requests: Dr GA Gould, Rayne Laboratory, Department of Respiratory Medicine, City Hospital, Edinburgh EH10 5SB.

Accepted 12 July 1985 automatically if inspiration is not detected over a 17 second period, delivering oxygen to the patient for a predetermined time. Both the 17 second delay and the oxygen delivery time are adjustable. This device, which is a prototype, measures $12 \times 10 \times 7 \mathrm{~cm}$ and weighs $1.3 \mathrm{~kg}$. The suppliers (Glasrock Home Health Care, Brentford, Middlesex) intend to produce a final version that is smaller and lighter and should cost around $£ 150$.

Device $B$ works on a principle similar to that of device $A$ but delivers a short burst of oxygen at a high flow rate at the beginning of inspiration. This device is the DOC (Demand Oxygen Controller), a demand type valve incorporated into a portable liquid oxygen system (Pulsair I), which is commercially available in the United States. (DOC and Pulsair are registered trade marks of $\mathrm{Cryo} / 2$ Corporation, Fort Pierce, Florida.)

Device $C$ is a modified nasal prongs system ("Oxymizer," Chad Therapeutics Inc, Woodland Hills, California), which incorporates a "moustache" oxygen reservoir that stores oxygen during expiration, so that a bolus of $20 \mathrm{ml}$ of about $85 \%$ oxygen is inhaled at the beginning of inspiration. It has been 
Table 1 Details of the patients

\begin{tabular}{|c|c|c|c|c|c|c|}
\hline \multirow[t]{2}{*}{$\begin{array}{l}\text { Patient } \\
\text { No }\end{array}$} & \multirow[t]{2}{*}{ Age } & \multirow[t]{2}{*}{ Sex } & \multirow[t]{2}{*}{$\begin{array}{l}F E V_{1} \\
(l)\end{array}$} & \multirow[t]{2}{*}{$\begin{array}{l}V C \\
(l)\end{array}$} & \multicolumn{2}{|c|}{$\begin{array}{l}\text { Arterial blood gas tension } \\
(\mathrm{kPa}) \text { breathing air }\end{array}$} \\
\hline & & & & & $\mathrm{PaO}_{2}$ & $\mathrm{PaCO}_{2}$ \\
\hline $\begin{array}{l}1 \\
2 \\
3 \\
4 \\
5 \\
6 \\
7 \\
8 \\
9 \\
10 \\
11 \\
12 \\
\text { Mean } \\
\text { SD }\end{array}$ & $\begin{array}{l}58 \\
89 \\
70 \\
70 \\
70 \\
66 \\
82 \\
65 \\
79 \\
61 \\
63 \\
70 \\
70 \\
9.05\end{array}$ & $\begin{array}{l}\mathbf{M} \\
\mathbf{F} \\
\mathbf{M} \\
\mathbf{M} \\
\mathbf{M} \\
\mathbf{M} \\
\mathbf{M} \\
\mathbf{M} \\
\mathbf{M} \\
\mathbf{M} \\
\mathbf{M} \\
\mathbf{M} \\
-\end{array}$ & $\begin{array}{l}0.4 \\
0.45 \\
0.48 \\
0.5 \\
0.55 \\
0.75 \\
0.75 \\
0.8 \\
0.9 \\
0.95 \\
1.5 \\
1.7 \\
0.81 \\
0.4\end{array}$ & $\begin{array}{l}2.5 \\
1.0 \\
2.0 \\
0.9 \\
2.5 \\
3.45 \\
2.05 \\
1.85 \\
2.6 \\
3.0 \\
4.1 \\
3.2 \\
2.43 \\
0.95\end{array}$ & $\begin{array}{l}8.2 \\
6.6 \\
8.7 \\
6.2 \\
7.5 \\
8.0 \\
7.3 \\
4.4 \\
6.9 \\
7.8 \\
8.0 \\
5.5 \\
7.1 \\
1.24\end{array}$ & $\begin{array}{l}5.8 \\
4.1 \\
5.2 \\
4.9 \\
4.5 \\
5.3 \\
6.2 \\
7.8 \\
4.8 \\
6.4 \\
4.2 \\
4.3 \\
5.3 \\
1.1\end{array}$ \\
\hline
\end{tabular}

VC-vital capacity; $\mathrm{PaO}_{2}$-arterial oxygen tension; $\mathrm{PaCO}_{2}$-arterial carbon dioxide tension.

Conversion-SI to traditional units: Blood gas tension-1 $\mathrm{kPa}=7.5 \mathrm{~mm} \mathrm{Hg}$.

reported to produce considerably higher arterial oxygen saturation levels than can be obtained by standard nasal prongs at the same oxygen flow rates. $^{4}$

\section{Methods}

We studied 12 patients with hypoxic chronic bronchitis and emphysema with a mean arterial oxygen tension $\left(\mathrm{PaO}_{2}\right)$ of 7.1 (SD 1.24) $\mathrm{kPa}(53(9) \mathrm{mm} \mathrm{Hg})$ and mean arterial carbon dioxide tension $\left(\mathrm{PaCO}_{2}\right)$ of $5.3(1.1) \mathrm{kPa}(40(8.3) \mathrm{mm} \mathrm{Hg})$ and a mean $\mathrm{FEV}_{1}$ of $0.8(0.4) 1$ after recovery from an acute episode of respiratory failure. At the time of the study all patients were receiving continuous low flow oxygen and were in a stable clinical state, as shown by spirometric values and arterial blood gas tensions (table 1). The study was carried out on two consecutive mornings, assessing devices $\mathrm{A}$ and $\mathrm{B}$ on one day and device $C$ on the other. The patients sat in a comfortable armchair and were allowed to adopt their normal breathing pattern, with no suggestion that they should breathe through the nose. Arterial oxygen saturation $\left(\mathrm{SaO}_{2}\right)$ was measured by a Hewlett-Packard 47201A ear oximeter.

In the assessment of devices $A$ and $B$ oxygen was delivered to the patient by standard nasal prongs from a $12 \mathrm{ft}^{3}(340 \mathrm{l})$ cylinder attached to an accurate pressure gauge, so that the amount of oxygen used could be calculated, to within 2 litres, from the pressure drop in the cylinder. The recording of a negligible pressure drop over 16 hours showed the delivery system to be leak proof. Oxygen was delivered either by continuous flow or by device $A$ or device $B$, each for a separate 40 minute period. The oxygen flow rate was set at $1 \mathrm{litre} / \mathrm{min}$ for 20 minutes and then increased to $2 \mathrm{l} / \mathrm{min}$ for a further 20 minutes. Oxygen consumption was measured from the pressure drop in the calibrated cylinder and $\mathrm{SaO}_{2}$ recorded at time zero and 20 and 40 minutes. $\mathrm{SaO}_{2}$ was continuously monitored to ensure that a stable baseline was achieved when the patient was breathing room air before each period of oxygen administration. In a separate study synchronisation of device A with the respiratory cycle was assessed in the 12 patients. Valve opening was detected by a photoelectric cell and recorded directly, with a simultaneous record of chest wall movement by the inductance plethysmograph (Respitrace Inc, Ardsley, New York). The flow characteristics and synchronisation of devices $A$ and $B$ were recorded in a normal subject by a Fleisch No 2 pneumotachograph interposed between the device and the nasal prongs.

To assess device $C$ each patient breathed oxygen on two occasions, one with device $C$ and the other with standard nasal prongs. The order of these two studies was assigned randomly. Oxygen was delivered from a $120 \mathrm{ft}^{3}(3400 \mathrm{l})$ cylinder, a calibrated rotameter being used that could measure to $0.05 \mathrm{~V}$ min (AP6222 flowmeter, Rotameter Manufacturing Co Ltd) at 0.5, 1.0, 1.5, 2.0, and 3.0 $/ \mathrm{min}$. At each flow rate the oxygen was continued until $\mathrm{SaO}_{2}$ became stable, at which time $\mathrm{SaO}_{2}$ was recorded, the flow rate then being increased to the next level. Before each study the baseline $\mathrm{SaO}_{2}$ when patients were breathing room air was stable for at least 30 minutes.

Statistical analysis of results was performed with Wilcoxon's signed rank test for paired differences. 

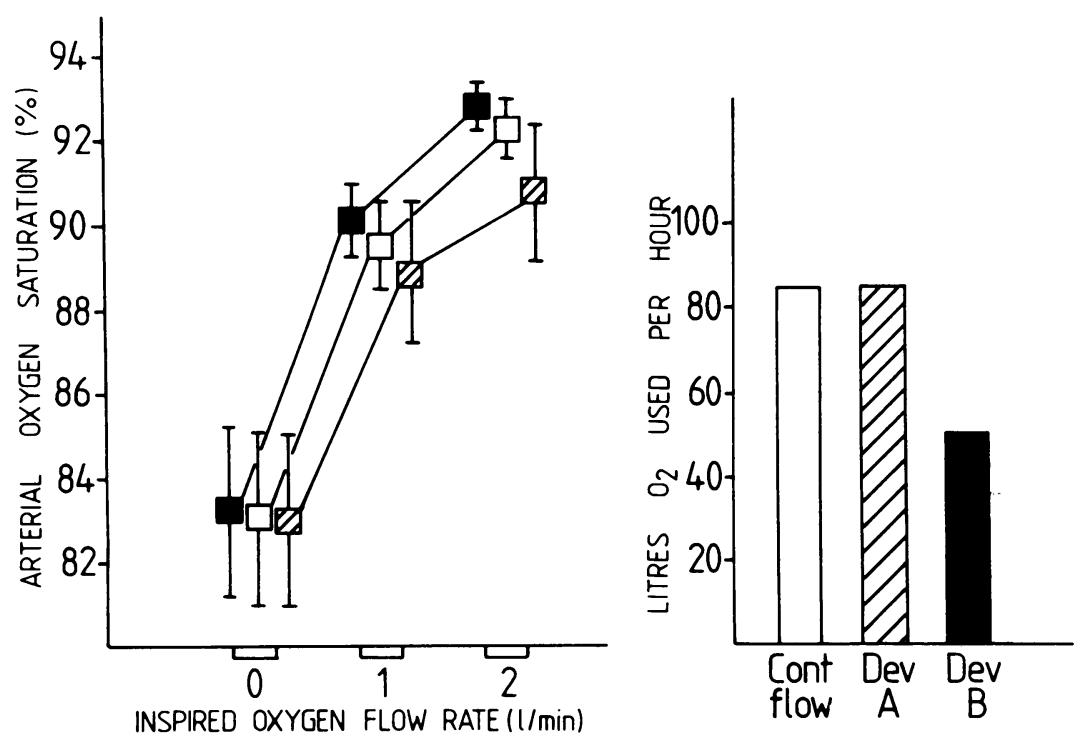

Fig 1 Comparison of arterial oxygen saturation achieved (mean and standard error) and oxygen used (mean) by device $A$, device $B$, and continuous flow. Open

symbols-continuous flow; hatched symbols-device A; solid symbols-device $B$.

\section{Results}

\section{Devices $A$ and $B$}

Arterial oxygen saturation rose in all patients when they were breathing oxygen supplied either by device A or B or by continuous flow. There was no significant difference between the three delivery systems in terms of the mean $\mathrm{SaO}_{2}$ achieved when they were breathing room air or oxygen at two flow rates (fig 1). Devices A and B could thus produce the same $\mathrm{SaO}_{2}$ as continuous flow oxygen. The amount of oxygen used over 40 minutes was $40 \%$ less ( $p<$ $0.01)$ with device $B$ than with continuous flow. With device A oxygen usage was the same as with continuous flow (fig 1).

In all 12 patients device $A$ achieved perfect synchronisation with respiration during resting tidal breathing, but at respiratory frequencies greater than 25 breaths/min the device intermittently failed to trigger. Studies in the normal subject confirmed that both device $\mathrm{A}$ and device $\mathrm{B}$ achieved perfect synchronisation during resting breathing, through the nose or mouth, but intermittently failed to trigger at respiratory frequencies greater than 25 breaths $/ \mathrm{min}$. Both devices continued to trigger at tidal volumes of $100 \mathrm{ml}$ and below, but an absolute

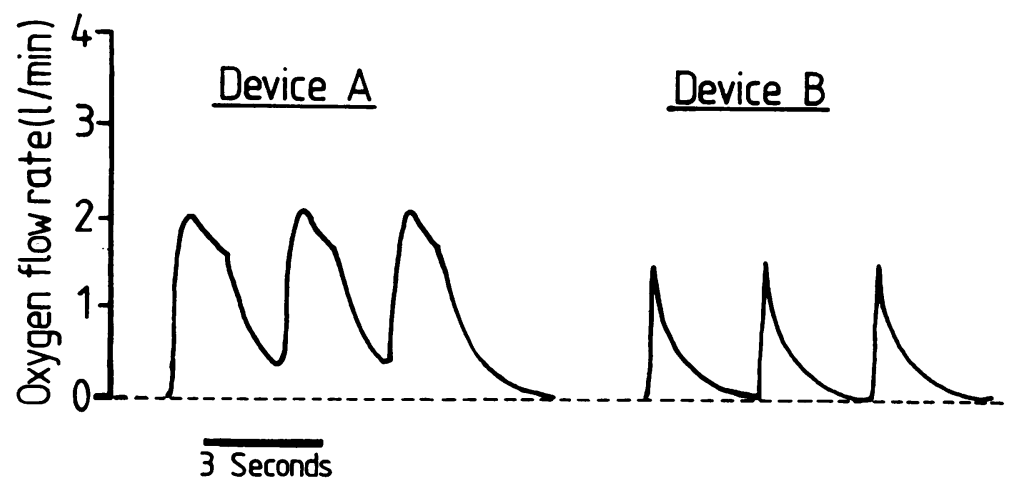

Fig 2 Flow characteristics of device $A$ and device $B$ recorded in a normal subject. 
Table 2 Rise in arterial oxygen saturation $\left(\mathrm{SaO}_{2}\right)$ at different oxygen flow rates with standard nasal prongs and with device $C$ (means with standard errors in parentheses)

\begin{tabular}{|c|c|c|c|}
\hline \multirow{2}{*}{$\begin{array}{l}\text { Oxygen } \\
\text { flow rate } \\
\text { (l/min) }\end{array}$} & \multicolumn{2}{|c|}{ Rise in $\mathrm{SaO}_{2}(\%)$} & \multirow{2}{*}{$\begin{array}{l}\text { Significance } \\
\text { (Wilcoxon signed } \\
\text { rank test) }\end{array}$} \\
\hline & $\begin{array}{l}\text { Nasal } \\
\text { prongs }\end{array}$ & Device C & \\
\hline $\begin{array}{l}0.5 \\
1.0 \\
1.5 \\
2.0 \\
3.0\end{array}$ & $\begin{array}{c}3.75(0.84) \\
6.67(1.18) \\
8.67(1.48) \\
9.83(1.85) \\
11.0(1.9)\end{array}$ & $\begin{array}{c}5.5(1.33) \\
8.42(1.67) \\
10.17(1.88) \\
11.16(2.0) \\
12.08(2.16)\end{array}$ & $\begin{array}{l}\text { NS } \\
\mathrm{p}<0.05 \\
\mathrm{p}<0.01 \\
\mathrm{p}<0.05 \\
\mathrm{NS}\end{array}$ \\
\hline
\end{tabular}

lower threshold for volume could not be accurately determined.

The flow characteristics of device A and device B are shown in figure 2 .

\section{Device $C$}

The mean baseline $\mathrm{SaO}_{2}$ during the breathing of room air was $82.6 \%$ for standard nasal prongs and $82.3 \%$ for device $\mathrm{C}$. $\mathrm{SaO}_{2}$ rose in all patients when they were breathing oxygen delivered by either method, though the mean rise in $\mathrm{SaO}_{2}$ at each flow rate of oxygen was higher with device $\mathrm{C}$ than with standard nasal prongs (table 2). Owing to the shape of the oxyhaemoglobin dissociation curve changes in $\mathrm{SaO}_{2}$

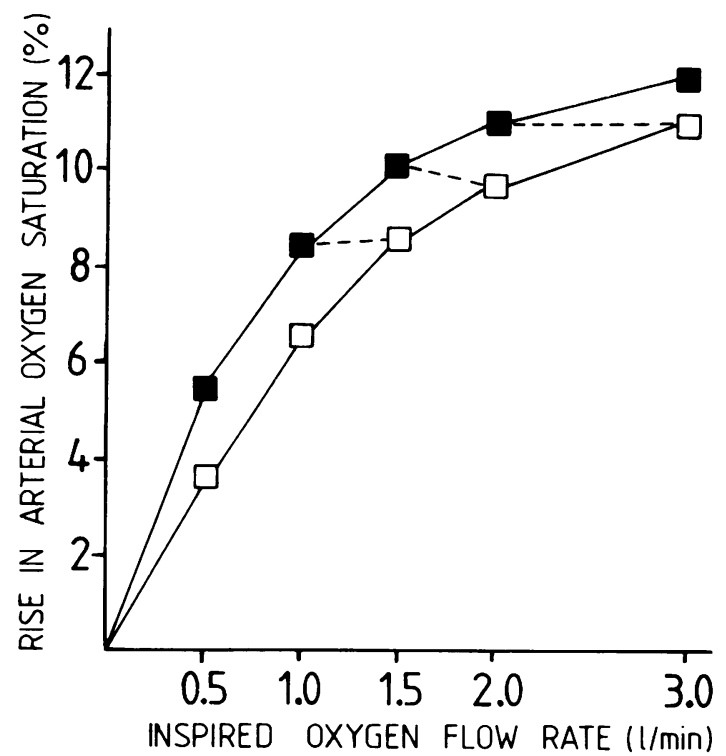

Fig 3 Comparison of mean rise in arterial oxygen saturation achieved at different oxygen flow rates by device $C$ and standard nasal prongs. Open symbols-standard nasal prongs; solid symbols-device $C$. The dotted line indicates no significant difference between data points. become blunted at higher oxygen flow rates, and this probably accounts for the insignificant difference observed between the $\mathrm{SaO}_{2}$ rise achieved by device $\mathrm{C}$ and by standard nasal prongs at a flow rate of $3 \mathrm{l} / \mathrm{min}$. Device $\mathrm{C}$ was thus able to achieve the same rise in $\mathrm{SaO}_{2}$ as standard nasal prongs at a lower oxygen flow rate, though the saving of oxygen was small (fig 3). It consistently achieved a greater increase in $\mathrm{SaO}_{2}$ than standard nasal prongs at all flow rates in five out of 12 patients. All patients commented that device $\mathrm{C}$ was more comfortable than standard nasal prongs.

\section{Discussion}

Oxygen that is delivered through the anterior nares during expiration may not take part in lung gas exchange. A device that restricts the delivery of oxygen to early inspiration should reduce the amount of oxygen lost in expiration. This could lead to a reduction in the cost of cylinder delivery systems and an increase in the operating time for portable liquid oxygen delivery systems, and possibly allow a reduction in size or power consumption, or both, of oxygen concentrators.

Various means of conserving oxygen by intermittent flow systems have been explored over the past 20 years, but none has yet been commercially exploited. Early devices worked by voluntary hand activation $^{5}$ or relied on chest wall movement for activation, ${ }^{6}$ thus making them obtrusive and often unacceptable to the patient. Encouraging results have been obtained with devices activated by temperature changes ${ }^{7}$ or pressure changes ${ }^{8}$ detected at the nostrils, but these devices relied on specially modified nasal prongs. Devices A and B are pressure activated, but can be used with standard nasal prongs, and though designed for use with cylinder or liquid oxygen supply could be modified for use with oxygen concentrators. Device $C$, a modified nasal prongs system, can be used with any form of oxygen supply, and does not add appreciable weight to the delivery system.

We find that device $A$ does not use less oxygen than a continuous flow of oxygen delivered through nasal prongs to produce the same $\mathrm{SaO}_{2}$. This is probably due to its flow characteristics, as it causes a more or less continuous flow of oxygen if the respiratory rate is rapid (fig 3 ). Our findings differ from those of Winter et al," who demonstrated a significant saving of oxygen when device $A$ was used to deliver oxygen at high flow rates over short periods of time $(2,4$, and $6 \mathrm{l} / \mathrm{min}$ for six minutes each).

Device $B$ uses $40 \%$ less oxygen yet achieves the same $\mathrm{SaO}_{2}$ as continuous flow of oxygen delivered by 
nasal prongs. All our patients were aware of the high flow rate of oxygen delivered at the onset of inspiration with device B but did not find this distressing, and it is unlikely to have any physiological effect.

Device $\mathrm{C}$ produced consistently greater increases in $\mathrm{SaO}_{2}$ levels in individual patients but this was not observed in all of our patients. The response was not correlated with age, $\mathrm{FEV}_{1}$ or $\mathrm{SaO}_{2}$ during the breathing of air and it may just reflect the proportion of time spent mouth breathing by the individual patient during the time of study, as prolonged mouth breathing may prevent any advantage from the "moustache" oxygen reservoir.

Patients with hypoxaemic chronic bronchitis and emphysema commonly suffer profound hypoxaemia during sleep, and these episodes may be related to hypoventilation or changes in the ventilationperfusion relationship (or both). An oxygen conserving device used in these patients should not exacerbate this, and since the three devices we studied continue to deliver oxygen even during hypoventilation this should not be a problem, though clinical studies during sleep are needed to confirm this.

We conclude that in 12 patients with hypoxaemia and severe airflow obstruction device $A$ was inefficient in conserving oxygen, though efficiency could be improved by altering its flow characteristics. Device B did conserve oxygen, yet maintained arterial oxygen saturation. Device $\mathrm{C}$ consistently achieved a greater rise in $\mathrm{SaO}_{2}$ than standard nasal prongs at the same oxygen flow rate in five of 12 patients, so saving some oxygen, but did not do this in seven similar patients.

Oxygen conservation can thus be achieved by some of these methods but further studies are needed to determine which system is likely to produce maximum cost effectiveness in long term clinical use.
We are grateful to the British Oxygen Company for supplying devices $A$ and $B$, and to Chad Therapeutics for their grant in aid support.

\section{References}

1 Nocturnal Oxygen Therapy Trial Group. Continuous or nocturnal oxygen therapy in hypoxaemic chronic obstructive lung disease: a clinical trial. Ann Intern Med 1980;93:391-8.

2 Medical Research Council Working Party. Long term domiciliary oxygen therapy in chronic hypoxic cor pulmonale complicating chronic bronchitis and emphysema. Lancet $1981 ; \mathrm{i}: 681-6$.

3 Department of Health and Social Security. Report No 4/9/176. December 1983.

4 Tiep BL, Nicotra B, Carter R, Belman MJ, Mittman C. Evaluation of a low flow oxygen-conserving nasal cannula. Am Rev Respir Dis 1984;130:500-2.

5 Cotes JE, Matthews CR, Tasker PM. Continuous versus intermittent administration of oxygen during exercise to patients with chronic lung disease. Lancet 1963;i:1075-7.

6 Pflug AE, Cheney FW jun, Butler J. Evaluation of an intermittent oxygen flow system. Am Rev Respir Dis 1972; 105:449-52.

7 Mecikalski M, Shigeoka JW. A demand valve conserves oxygen in subjects with chronic obstructive pulmonary disease. Chest 1984;86:667-70.

8 Auerbach DVM, Flick MR, Block AJ. A new oxygen cannula system using intermittent demand nasal flow. Chest 1978;74:39-44.

9 Winter RJD, George RJD, Moore-Gillon JC, Geddes DM. Inspiration-phased oxygen delivery. Lancet 1984;ii: 1371-2.

10 Douglas NJ, Leggett RJE, Calverley PMA, Brash HM, Flenley DC, Brezinova V. Transient hypoxaemia during sleep in chronic bronchitis and emphysema. Lancet 1979; i: $1-4$.

11 Catterall JR, Douglas NJ, Calverley PMA, et al. Transient hypoxaemia during sleep in chronic obstructive pulmonary disease is not a sleep apnoea syndrome. $\mathrm{Am}$ Rev Respir Dis 1983;128:24-9. 